\title{
"ORDEM", DE LEUSA ARAUJO: VIOLÊNCIA SIMBÓLICA E O INSUCESSO DA BILDUNG EM TEMPOS DE DITADURA CILVIL-MILITAR
}

\author{
"ORDER", BY LEUSA ARAUJO: SYMBOLIC VIOLENCE AND BILDUNG'S FAILURE \\ IN TIMES OF CITIZEN-MILITARY DICTATORSHIP
}

Recebido: 13/01/2021

Aprovado: 17/05/2021

Publicado: $30 / 07 / 2021$

DOI: $10.18817 /$ rlj.v5i01.2568

\author{
Rafael Lucas Santos da Silva ${ }^{1}$ \\ http://orcid.org/0000-0002-1245-8284
}

\begin{abstract}
Resumo: Leusa Araujo escolheu o passado histórico da Ditadura Civil-Militar (1964-1985) como cenário para a narrativa juvenil do seu romance Ordem, sem lugar, sem rir, sem falar. Por ser uma obra voltada ao público juvenil, Leusa Araujo amplia o olhar para além da condição daqueles que sofreram a experiência física da tortura e do assassinato, abarcando os dilemas afetivos de um personagem cuja transição da infância à adolescência ocorre justamente nos anos de chumbo da Ditadura. Por isso, o objetivo deste artigo foi realizar uma abordagem crítica ao romance a partir da noção de Bildungsroman. $O$ termo Bildungsroman surge associado à obra Os anos de aprendizado de Wilhelm Meister (1795-1796), de Goethe (1749-1832), e tem sido importante para compreensão da produção literária juvenil contemporânea, conforme estudos de Delbrassine (2006) e Cruvinel (2009). Partindo do pressuposto do caráter dinâmico do Bildungsroman (MAAS, 2000), este artigo norteia-se pela hipótese de que o romance de Leusa Araujo subverte e problematiza o processo de formação, optando pelo insucesso da Bildung do protagonista. Acreditamos que isso ocorre devido a figuração da própria memória autoritária da Ditadura Civil-Militar, de modo que para fazer a comprovação, também recorremos à noção de violência simbólica de Bourdieu (1989; 2003).
\end{abstract}

Palavras-Chave: Literatura juvenil. Leusa Araujo. Bildungsroman. Ditadura Civil-Militar. Violência simbólica.

\begin{abstract}
Leusa Araujo chose the historical past of the Civil-Military Dictatorship (1964-1985) as the setting for the youthful narrative of her novel Order, without place, without laughing, without speaking. As a work aimed at the youth audience, Leusa Araujo expands the look beyond the condition of those who suffered the physical experience of torture and murder, embracing the emotional dilemmas of a character whose transition from childhood to adolescence occurs precisely in the lead years of the Dictatorship. For this reason, the aim of this article was to take a critical approach to the novel based on the notion of Bildungsroman. The term Bildungsroman becomes well known when associated with Goethe's Wilhelm Meister's Apprenticeship Years (1795-1796), and has been important for understanding contemporary youth literary production, according to studies by Ceccantini (2000), Delbrassine (2006) and Cruvinel (2009). Based on the assumption of the dynamic character of Bildungsroman (MAAS, 2000), this article is guided by the hypothesis that Leusa Araujo's novel subverts and problematizes the formation process, opting for the protagonist's Bildung failure. We believe that this occurs due to the figuration of the authoritarian memory of the Civil-Military Dictatorship, so that in order to prove it, we also resort to the notion of symbolic violence by Bourdieu $(1989 ; 2003)$.
\end{abstract}

Keywords: Youth literature. Leusa Araujo. Bildungsroman. Civil-Military Dictatorship. Symbolic violence.

1 Realiza doutoramento na área de Estudos Literários, na Linha de Pesquisa Literatura e Historicidade, pelo Programa de Pós-Graduação em Letras da Universidade Estadual de Maringá (UEM). É Mestre em Letras (UEM), com dissertação intitulada A insígnia de medalhão nos contos de Machado de Assis pelo prisma do Materialismo Lacaniano. Possui Graduação em Letras Português/Espanhol e Respectivas Literaturas na Universidade Estadual do Oeste do Paraná UNIOESTE, Campus de Foz do Iguaçu. E-mail: i3rafael@hotmail.com 


\section{Considerações iniciais}

De súbito é o susto

estampado no rosto refletido no espelho parado na garganta. Invasores transitam pelo quarto desrespeitam o sono em furor incontido. Colocam algemas em pulsos inocentes. Contra palavras - há muros contra lamentos, murros.

Levam jovens na mira de fuzis reluzentes.

Lara Lemos (1997)

Ordem, sem lugar, sem rir, sem falar é o segundo romance de Leusa Araujo, publicado em 2010². Formada em jornalismo, estreou como escritora em 1994, aos 34 anos, com o romance Agitação à Beira-mar. Leusa Araujo vem se dedicando à produção literária juvenil, com as publicações de $A$ cabeleira de Berenice (2006), indicado para o Prêmio Jabuti, em 2007, na categoria "Melhor Juvenil", Náufragos emergentes: seis histórias ordinárias (2009), Ordem, sem lugar, sem rir, sem falar (2010), Cida, a empreguete: Um diário íntimo (2012) e Senão eu atiro - e outras histórias verídicas (2017) 3 .

Composto por 34 capítulos, em uma estrutura fragmentária de textos curtos, o romance Ordem desenvolve uma história situada em São Paulo, entre 1968 e 1972, com um narrador autodiegético. Publicado em 2010, o romance de Leusa Araujo insere-se na mobilização de ficções contemporâneas frutíferas do ponto de vista analítico para representações complexas e multifacetadas das experiências vividas sob a Ditadura, surgida devido a completar-se tanto os trinta anos da promulgação da Constituição quanto o cinquentenário do golpe civil-militar de 1964. Perlatto (2017) argumenta que "houve uma espécie de boom na publicação de romances que elegeram a ditadura como contexto e cenário das narrativas ficcionais" (PERLATTO, 2017, p. 729), e explica quanto a isto:

\footnotetext{
2 Daqui em diante nos referiremos ao romance apenas como Ordem, conforme o título do artigo.

${ }^{3}$ Além de contar também com publicações não ficcionais voltadas ao público juvenil, como Tatuagem, Piercing e outras mensagens do corpo (2005), considerado altamente recomendável pela Fundação Nacional do Livro Infantil e Juvenil (FNLJ) na categoria informativo, O Livro do Cabelo (2012), uma interessante pesquisa sobre a história social do cabelo, e Convivendo em grupo: almanaque de sobrevivência em sociedade (2015), com o qual conquistou o Prêmio Jabuti (2016), em segundo lugar na categoria Didáticos e Paradidáticos.
} 
Este boom pode estar associado ao interesse editorial no sentido de se aproveitar as rememorações em torno do cinquentenário do golpe de 1964 para a publicação de livros relacionados a esta temática, ou pode ser vinculado a um movimento geracional de escritores que não vivenciaram diretamente os anos repressivos e que vêm procurando, via ficção, lidar com esse passado autoritário (PERLATTO, 2017, p. 729).

Seja qual for o motivo, consideramos o romance Ordem como um fundamental auxílio simbólico para enfrentar e denunciar esse horrendo e traumático período de nossa história como nação. A peculiaridade a partir da qual o romance Ordem realiza essa tarefa não consiste, afinal, em trilhar o caminho do romance histórico tradicional, lançando mão de detalhes documentais, pois sua proposta ficcional não é a representação de circunstâncias sociopolíticas e históricas desse período traumático da vida brasileira. Ou seja, não encontramos ao longo da narrativa registros sobre tortura, luta armada, a censura, presos políticos, exílios, entre outros.

A peculiaridade do romance, portanto, encontra-se na construção dos dilemas afetivos do protagonista, cujo recurso do narrador autodiegético visa pautar a narrativa pela introspecção psicológica, expondo a configuração do perfil da identidade do protagonista a partir de suas relações na vida familiar, doméstica, e na escola, que são os espaços sociais privilegiados pela narrativa de Leusa Araujo. Compreendemos esse aspecto na esteira de Jameson (2007), no sentindo em que no romance o passado histórico ficcionalizado é resultante do entrecruzamento do "plano existencial da vida individual", ainda que, no caso, sujeitos sejam ficcionais, com o "plano histórico transindividual" (JAMESON, 2007, p. 190)

Dessa forma, concebemos haver um entrecruzamento na narrativa entre a linha de romance histórico e a linha psicológica, que enseja profícuas discussões. A nossa hipótese de leitura consiste, pois, em propor que a forma específica pela qual se configura a combinação dessas duas linhas implica em uma subversão do Bildungsroman, ao problematizar a formação/identidade adolescente em contexto autoritário. Como a narrativa não enfoca cenas de violência física, explicitações de agressão, ou de imagens de militares armados, fez-se ser necessário recorremos à noção de violência simbólica de Bourdieu (1989; 2003). Se o tema do Bildungsroman é o personagem passar por um processo de formação, então como pode o adolescente Doca formar uma identidade crítica e autônoma quando se está 
institucionalizado no país práticas autoritárias? Como pode haver Bildung em um período que deformou a condição humana, reduzindo o sujeito a mero objeto e incapacitando-o para a ação política a partir do arbítrio autoritário?

A fim de preparar o terreno para explorarmos essas questões a partir da estrutura literária do romance, apresentaremos rapidamente que o Bildungsroman possui uma historicidade, o que permite compreender o caráter dinâmico, ao invés de estático, do gênero.

\section{O caráter dinâmico do Bildungsroman}

Bildungsroman é um termo alemão que se consolidou no vocabulário acadêmico desde a segunda metade do século XIX, sendo cunhado pela justaposição de Bildung (formação) e Roman (romance) a partir de um forte otimismo com os princípios iluministas e compromissos pedagógicos.

Em O cânone mínimo. O Bildungsroman na história da literatura, Wilma Maas (2000) realiza um trabalho exitoso de divulgação e sistematização cientifica pioneiro no Brasil sobre a temática do Bildungsroman. Seu propósito foi o de empreender "uma investigação que se baliza pelo reconhecimento da historicidade do Bildungsroman" (MAAS, 2000, p. 17), possibilitando, assim, a compreensão de que esse gênero surgiu em uma instituição-literária, composta pelo conceito histórico de Bildung burguesa, fundamental para o funcionamento da sociedade absolutista tardia da Alemanha do final do século XVIII, e pela grande instituição literária do mundo moderno, o romance.

Em conformidade com a autora, a definição inaugural do termo Bildungsroman foi realizada por Karl Morgenstern (1770-1852), que o cunhou para designar a formação do protagonista em seu início e trajetória até alcançar um determinado grau de perfectibilidade. Apesar de ter cunhado o termo em uma conferência de 1810, a noção de Bildungsroman só foi inserida efetivamente no discurso acadêmico em 1870 devido a Wilhelm Dilthey (1833-1911), de modo que ambos consolidam uma concepção literária que reconheceria a obra Os Anos de Aprendizado de Wilhelm Meister, de Goethe, como o paradigma desse gênero, que possui a noção de processo como algo fundamental: "processo, neste contexto, é a sucessão de etapas, teleologicamente encadeadas, que compõe o aperfeiçoamento do indivíduo em direção à harmonia e ao conhecimento de si e do mundo. Formação 
(Bildung) passa então a dialogar com educação (Erziehung)" (MAAS, 2000, p. 27).

Ao buscar a historicidade desse aspecto, Maas (2000) assinala que essa relação entro formação e educação surge em um momento em que a burguesia deixa de se preocupar somente "com a acumulação de riquezas para desejar a posse de conhecimento", de maneira tal que é possível compreender que a inscrição de Os anos de aprendizado de Wilhelm Meister sob o termo genérico romance de formação "reflete esse momento histórico particular, quando a preocupação burguesa com o (auto-) aperfeiçoamento encontrava-se manifesta tanto no discurso teórico quanto nas reformas que então se ensejavam, nomeadamente no âmbito da educação e instrução" (MAAS, 2000, p. 34).

Conforme Maas (2000), é necessário não esquecer a historicidade que envolve a criação do termo, dado que seu aspecto ideológico possui raízes vincadas em circunstâncias históricas, culturais e literárias dos últimos trinta anos do século XVIII europeu. Dentre essas circunstâncias, destaca-se a constituição da burguesia e o reconhecimento do romance como forma "digna":

A criação do termo Bildungsroman emerge, portanto, como um fato histórico associado a esse momento do pensamento burguês, em que a preocupação com a acumulação de riquezas passa a coexistir com um desejo de superação dos limites do conhecimento possível à classe média ascendente. A origem da "literatura de formação" pode ser compreendida como resultado de um mecanismo social auto-reflexivo desenvolvido por uma classe que quer ver espelhados seus próprios ideais na ficção de cunho realista que começa a firmar-se como gênero (MAAS, 2000, p. 44)

Percebe-se, assim, o surgimento desse gênero estreitamente vinculado com ideologias do século XVIII, mas isso, por outro lado, não anulou a possibilidade de manutenção do gênero, e isto "significa que a existência do Bildungsroman como gênero é possível apenas se admitirmos uma contínua alteração de seus pressupostos" (MAAS, 2000, p. 63). É argumentado pela autora que "a história da continuidade do Bildungsroman no século XX reitera o caráter dinâmico e empírico do gênero" (MAAS, 2000, p. 81).

São imprescindíveis essas atualizações/subversões, uma vez que, no século $X X$, "a representação do desenvolvimento individual como um processo linear em direção ao equilíbrio das tendências individuais no enfretamento com a sociedade torna-se então uma aporia" (MAAS, 2000, p. 81). Nesse aspecto, é importante lembrar que ocorreram transformações fundamentais durante o século $X X$, ao ponto 
de Hobsbawn (1995) utilizar a expressão "revolução cultural" para designar tais transformações. Sobre o período que surge do imediato pós-Segunda Guerra (1947), o historiador inglês denominou a "Era de Ouro", pois configurou-se como os "anos de extraordinário crescimento econômico e transformação social, anos que provavelmente mudaram de maneira mais profunda a sociedade humana que qualquer outro período de brevidade comparável" (HOBSBAWM, 1995, p. 15). Em conformidade com o autor, houve uma "revolução cultural", determinante na configuração de novas maneiras de compreender a sociedade e que "pode ser mais bem entendida como o triunfo do indivíduo sobre a sociedade, ou melhor, o rompimento dos fios que antes ligavam os seres humanos em texturas sociais" (HOBSBAWM, 1995, p. 328).

Compreender as transformações sociais, econômicas e histórico-culturais é fundamental, dado que as "subversões se devem necessariamente ao dinamismo do gênero em meio às diferentes constelações histórico-literárias" (MAAS, 2000, p. 81). Isso posto, reconhece-se equivocada uma compreensão do Bildungsroman como uma manifestação cristalizada e imutável.

Assim, o gênero "sobrevive necessariamente por sua própria transgressão" (MAAS, 2000, p. 248), o que implica uma espécie de "mecanismo de atualização" (MAAS, 2000, p. 63), de modo que

Esse mecanismo possibilita por sua vez que se possa falar em um Bildungsroman feminista, em um Bildungsroman proletário, em um Bildungsroman "psicanalítico". Assim, cada época, cada configuração histórica e intelectual pode ter seu próprio Bildungsroman, na medida em que recorre aos princípios fundamentais capazes de definir o conceito, necessariamente transformando-os ou mesmo subvertendo-os (MAAS, 2000, p. 253).

Com efeito, ao concordarmos com essa perspectiva da historicidade do Bildungsroman, podemos refletir sobre como o gênero é elaborado ao público juvenil, bem como ponderar a sua relação com o período da Ditadura Civil-Militar brasileira.

\section{Doca, uma juventude mutilada pela Ditadura Civil-Militar?}

A estreia de Leusa Araújo como escritora, em 1994, coincide com o momento de consolidação e modificação da produção da literatura juvenil, em que se verifica o 
aumento da complexidade narrativa, devido às inovações encontradas em termos de caracterização das personagens, atuação do narrador, tipos de desfechos e cenários dessa contemporânea produção literária juvenil.

Colomer (2003) assinala que esse aumento da complexidade narrativa corresponde, pois, a modificação do público de crianças e jovens próprios das sociedades contemporâneas, "a quem se destinam textos que refletem as mudanças sociológicas e os pressupostos axiológicos e educativos de nossa sociedade pósindustrial e democrática" (COLOMER, 2003, p. 174).

Diante disso, compreende-se que o trabalho de Leusa Araújo, no romance Ordem, busca alcançar uma complexidade dos elementos que configuram o discurso narrativo, visto que se afasta dos pressupostos básicos "de uma estrutura simples, um ponto de vista onisciente, uma voz narrativa ulterior e um desenvolvimento cronológico linear" (COLOMER, 2003, p. 176).

Doca é o protagonista do romance Ordem. Ele possui uma irmã, Elisa, e seus pais não são nomeados na narrativa. Sua infância não está relacionada a temática da imaginação ou fantasia, mas ao reconhecimento que se efetiva a partir do que observa na sua família e vivencia na escola. Doca é um narrador autodiegético, já que relata as próprias experiências como personagem, de modo que, ao longo dos 34 capítulos do romance, Doca é o filtro quantitativo e qualitativo que conduz a representação narrativa. Contudo Doca não está distanciado no tempo, narrando sua adolescência retrospectivamente. Conforme os estudos de Reuter (1995), compreendemos que Ordem possui uma temporalidade simultânea ao utilizar uma narração autodiegética centrada no personagem, uma vez que "ele narra a sua história como se ela desenrolasse no momento da narração. Constrói-se uma ilusão de simultaneidade entre os acontecimentos e sua narrativa" (REUTER, 1995, p. 77).

A peculiaridade literária do romance vincula-se à temática, ou, pode-se dizer, proposta ficcional. Essa proposta ficcional pauta-se, pois, no "autoritarismo" e na "violência da repressão" da Ditadura Civil-Militar, conforme o enunciado da autora no prefácio do romance:

Esta história se passa entre os anos de 1968 e 1972, durante a ditadura militar brasileira, um tempo difícil de viver quando se é criança. [...] A escola nos anos de chumbo é outra, muito diferente da de hoje. É no seu interior que o autoritarismo se manifesta, um dia após o outro, com sua velha pedagogia do medo e dos portões fechados. A violência da repressão ora gritante, ora silenciosa - transbordou para as ruas, invadiu nossas 
casas, bateu portas, sentou-se à mesa de jantar, dificultou os relacionamentos, e criou, infelizmente, maneiras que você de controlar o futuro (ARAUJO, 2010, s/p.).

O que significar exatamente "violência da repressão"? A pergunta é importante na medida em que no romance não é representado, por exemplo, a violência da tortura. Concebemos que o propósito não é retratar a violência física direta, mas podemos apreender que há uma violência simbólica contra Doca, que bem compreendida permite validar a nossa hipótese do insucesso da sua Bildung.

Isso implica em identificar na vivência de Doca como o arbítrio autoritário da Ditadura é exercido a partir de uma violência simbólica, o que faremos tendo como baliza as reflexões de Bourdieu (1989; 2003). Para o sociólogo, a violência simbólica pode ser compreendida como uma "violência suave, insensível, invisível a suas próprias vítimas, que se exerce pelas vias puramente simbólicas da comunicação e do conhecimento, ou mais precisamente, do desconhecimento, ou, em última instância, do sentimento" (BOURDIEU, 2003, p. 7-8).

A violência simbólica é exercida de modo que os sujeitos construam suas trajetórias de vida assegurando a reprodução social. Esse aspecto condiz com o fato de que as relações familiares e a escola são os espaços sociais privilegiados pelo romance, durante os cinco anos em que transcorre a história do romance. Esses cinco anos é o período conhecido como o mais repressivo da Ditadura, devido ao Ato Institucional o 5 (AI-5), promulgado em 1968.

A Ditadura Civil-Militar iniciou-se em 1964, a partir de um golpe das Forças Armadas apoiado por setores industriais e civis, estendendo-se por 21 anos. Compreendido entre 1968 a 1974, os "anos de chumbo" constituem o momento de maior repressão da Ditadura, inserindo-se, inclusive, no cotidiano da população como silenciamento pelo medo. O propósito ficcional não é ser um documentarismo fiel aos fatos objetivos da repressão política durante os anos de chumbo. Como já apontado, a autodiegese de Doca é centrada em seus próprios dilemas afetivos. Apesar da quantidade de referências que se reconhecem como reais ${ }^{4}$, o romance trata de distanciar-se dessa realidade referencial.

No primeiro capítulo (“Ordem”), a escola já é exposta como um ambiente

\footnotetext{
${ }^{4}$ Ao longo do romance, nos deparamos com diversos aspectos históricos factuais: sapato Vulcabrás, Manual do escoteiro mirim, Mappin (loja de departamentos), "Sugar, sugar" (canção de Andy Kim e Jeff Barry), "Brasil, eu fico" (canção gravada por Wilson Simonal), Programa da Hebe, Enciclopédia Barsa, a chegada dos astronautas à lua, Presidente Médici, entre outros.
} 
opressivo, com destaque ao inspetor Paulão, que "fica fungando na orelha da gente, dando bronca sem parar" (ARAUJO, 2010, p. 10). O comportamento agressivo de Paulão visa garantir a ordem, como dispositivo disciplinador das posturas e atitudes dos alunos, por isso Doca diz evitar, inclusive, brincadeiras com seus colegas para não correr o risco de levar bronca do Paulão. Ao chegar na escola, tudo gira em torno da consecução da ordem, conforme a primeira frase do romance: "Maio de 1968 é o grande pátio da escola, vozes estridentes, professores e inspetores de alunos com réguas de madeira na mão para fazer a formação da fila de entrada" (ARAUJO, 2010, p. 10).

A régua de madeira, instrumento de punir os alunos, surge como hábito, para amenizar a estridência desses alunos. O termo "Maio de 1968", com o qual se inicia o romance, remete à acontecimentos de efervescência social e política global, bem como a violência que se intensificava na Ditadura e que podem ser compreendidas nas ações do inspetor Paulão: "Ele diz o tempo todo que somos um estorvo na vida dele. Que ele não aguenta mais ver um moleque pela frente. Que é só abrir o portão da escola e ver aquela cambada junta que ele tem vontade de sair descendo 0 sarrafo!" (ARAUJO, 2010, p. 10-11). Pensar "Maio de 1968" também implica levar em conta o assassinato do estudante Edson Luís de Lima Souto, de 18 anos, no mês de março daquele ano, que jantava no restaurante Calabouço, no prédio da União Nacional dos Estudantes (UNE), no Rio de Janeiro, local onde, durante uma manifestação, foi atingido com um tiro no peito por policiais militares. Esse assassinato desencadeou diversos protestos no país contra a violência policial, cuja resposta, aos discursos antimilitares no Congresso Nacional, foi o promulgamento do Ato Institucional $\mathrm{n} . \stackrel{0}{5}$, que marcou o endurecimento do regime, realizando a institucionalização da tortura, prática que já era adotada regularmente pelos oficiais militares. Práticas de tortura que podemos compreender como figurada na cena de truculência de Paulão ao ter que fazer estancar um sangramento do nariz de Doca. Nesse momento de fragilidade, ocorrido por algum motivo não mencionado, Paulão violenta-o ainda mais:

Ele me olhava impaciente vendo o sangue teimoso escorrer na camisa branca. Enfiava de uma vez a minha cabeça na água. Enfiava de novo e ficava segurando até eu engasgar com tanto jato de água. Fui tomado de um acesso de tosse. Paulão ficou mais nervoso ainda. Que eu parasse de tossir. Que ele não era enfermeiro. Que eu era um moleque fracote de merda, isso, sim, que eu era. E que eu tratasse de me enxugar na camisa, 
que frescura eu lá com a cara molhada. Só Ihe faltava essa, um moleque chorando, com as mãos aflitas, parecendo um pato assustado... (ARAUJO, 2010, p. 11).

Doca é subjugado numa relação de domínio e controle, sendo ainda ameaçado para não "reclamar" para seus pais sobre o ocorrido, senão poderia passar por uma situação pior. "Nunca abri o bico, pato assustado. Nem para mamãe, quando me perguntou por que é que o uniforme estava tão engruvinhado e com manchas de sangue na camisa", expõe, com efeito, Doca, que finaliza esse primeiro capítulo desabafando que começou a "rezar a noite inteira pedindo a Deus Pai que nunca mais me mandasse para a escola" (ARAUJO, 2010, p. 13).

Isso indica o trauma sofrido por Doca, não à toa o espaço escolar será tratado em sua autodiegese em apenas mais três capítulos ("Q.l", "Foi então que adoeci" e "A professora de francês"), nos quais ocorrem, novamente, cenas de humilhação e sofrimento. No capítulo "Q.l", Doca narra que fez um desenho em uma atividade escolar, a partir do qual a direção do colégio o considerou como um menino prodígio: "Q.I. avançado para minha idade: a inteligência de um garoto de pelo menos catorze anos" (ARAUJO, 2010, p. 39). Contudo, isso que o havia deixado "feliz", também foi o motivo do seu sofrimento: primeiramente, devido a um excesso de estudos, porque Doca resolveu "que seria capaz de decorar dicionários, tabuadas" e isso "trouxe dores de caneca e certos enjoos" a ponto de ter "recomendações médicas para que eu parasse de ler" "ARAUJO, 2010, p. 40); o segundo motivo foi "ter sido o inimigo número um da professora substituta" (ARAUJO, 2010, p. 41). Conforme seu relato, a professora substituta começou a provocá-lo depois de ter apontado que ela tinha errado a resolução de um exercício de matemática. Por isso,

[...] aquela mulher tanto fez, tanto provocou, que acabou me tirando da escola. É isso aí. Eu, o gênio, disse que o problema de matemática estava errado na lousa (e estava mesmo, eu fiz a prova dos nove). E ela, a substituta, resolveu me desafiar. $\mathrm{E}$, definitivamente, mostrar para todos os meus colegas invejosos que eu era mesmo um moleque chato e mimado pela professora e que, com ela, ia ser muito diferente (ah, ia!): eu ia tirar nota baixa, como todo mundo (ARAUJO, 2010, p. 42).

Doca diz nunca ter entendido por que a professora começou a "provocá-lo", já que não havia intenção de inferiorizar a professora ao sinalizar o erro do exercício de matemática. Os momentos de exposição e ridicularização de Doca na frente dos 
alunos causaram-Ihe muitos sofrimentos, psicológicos e físicos:

[...] dores de cabeça, tonturas, vontade de nunca mais sair da cama. É isso o que eu sinto. Uma cabeça estreita, onde não cabem tantas coisas assim como eu pensava. Por ter um Q.I anormal, de catorze anos, é claro que a quantidade de estudos e de decoreba acabaram por inchar a minha mente. Daí as dores de cabeça latejantes que eu comecei a sentir cada vez que a professora vinha com mais uma chamada oral. Ela passou a fazer chamadas orais diárias, só para mim. Nunca entendi. A classe, é claro, achava o máximo. Ninguém tinha mais tinha que fazer nada. Só aplaudir a professora toda vez que eu errasse. Eles riam. E eu sentia enjoo, vontade de chorar, e pedia para sair da sala. A bruxa não permitia. Preferia me deixar de castigo, de frente para a lousa, para que meus coleguinhas observassem como minhas pernas tremiam. Quando saí da classe, o pior aconteceu: mijei nas calças na hora do recreio, na fila do banheiro e no caminho de casa. Falei para mamãe que eu derrubara o suco. "Três vezes?", ela estranhou. "Três", eu jurei, pondo eu mesmo a calça dentro do tanque (ARAUJO, 2010, p. 43)

Momentos como esse fizeram Doca pegar um atestado para ficar um bom período sem ir na escola. $O$ ato de violência contra Doca ao mesmo tempo também reafirma o poder simbólico da professora, uma vez que não é apenas Doca o atingido, os outros alunos compreendem simbolicamente que não podem contestar a professora para não passarem pela mesma exposição e ridicularização. A mesma situação de violência simbólica ocorre no capítulo "A professora de francês", em que a professora é o "maior pesadelo" da sala (ARAUJO, 2010, p. 71).

Nesses capítulos, estamos diante claramente de momentos de violência simbólica, reproduzindo humilhação e medo como estratégia de legitimação do poder da professora, e do colégio como um todo. Os três capítulos, dos 34, que tratam da escola - apesar de não mencionar conteúdo ensinado, professores que pudessem explicitamente defender ou contrariar a Ditadura - apresentam-na em uma dinâmica funesta, onde o risco de humilhação é eminente. Portanto, o espaço escolar, em vez de ser o lugar onde se formará um pensamento crítico sobre a sociedade, acaba por reproduzir, na verdade, a mesma lógica de uma sociedade arbitrária, violenta e opressora.

"Bom de comércio" e "Brasil eu fico" são os capítulos na sequência de "A professora de francês" e revelam outros mecanismos utilizados para legitimar o projeto de desenvolvimento do poder dos militares, que foi a Copa de 1970 e uma música gravada por Wilson Simonal ("Este é o meu Brasil, /Futuro progresso do ano 2000. /Quem não gostar e for contra/Que vá pra..."). A música "Brasil eu fico" começa conclamando os diferentes estados da União para cantarem em coro "as 
riquezas mil" do país e, assim, a música faz referência positiva ao slogan "Brasil, ame ou deixe-o".

A referência a esse slogan também surge no capítulo "A parada", ao relatar que seu pai estava "de prontidão" para assistir "à parada militar na tevê" em comemoração ao 7 de Setembro. Assistir a transmissão da parada militar é um momento de lazer para família. Doca faz referência a uma canção que estava aprendendo e ensaiando na escola em comemoração à essa data, que se trata da canção "Eu te amo, meu Brasil", composta em 1970 pela dupla Dom e Ravel (Eu te amo meu Brasil, eu te amo / Meu coração é verde, amarelo, branco, azul anil / Eu te amo meu Brasil, eu te amo / Ninguém segura a juventude do Brasil”). Conforme Duarte (2006), essa canção era transmitida muito frequentemente por meio da TV, além de ser obrigada a ser cantada nas escolas, como acontece com Doca:

A canção "Eu te amo meu Brasil", divulgada à exaustão nas rádios na gravação de Don e Ravel, ou dos Incríveis, e que era cantada também nos colégios, incentivada implícita ou explicitamente pelas autoridades educacionais no poder, nos chamados anos de chumbo - o que levou a trágica condição de hino não oficial do Regime Militar (DUARTE e GONZALEZ, 2006, p.52).

Podemos compreender, à luz de Adorno e Horkheimer (1985), essa colocação de Duarte (2006) como um sinal de bens culturais massificados em favor do regime ditatorial. Percebemos, assim, o rádio e a televisão, como meios de comunicação, legitimando o poder simbólico do poder militar com essa divulgação exaustiva, que "favorece a resignação, que nela quer ser esquecer" (ADORNO e HORKHEIMER, 1985, p. 117).

Dessa forma, nesses sete capítulos analisados (“Ordem”, "Q.l”, "Foi então que adoeci", "A professora de francês", "Bom comércio", "Brasil eu fico" e "A parada"), vêse, portanto, o espaço escolar e o lazer em que está inserido Doca, servindo como sistemas simbólicos de legitimação do poder da Ditadura, dado que segundo Bourdieu (1989):

É enquanto instrumentos estruturados e estruturantes de comunicação e de conhecimento que os sistemas simbólicos cumprem a sua função política de instrumentos de imposição ou de legitimação da dominação, que contribuem para assegurar a dominação de uma classe sobre outra (violência simbólica) dando o reforço da sua própria força às relações de força que as fundamentam e contribuindo assim, segundo a expressão de Weber, para a "domesticação dos dominados" (BOURDIEU, 1989, p. 11). 
Ao concordarmos na potência do poder simbólico e como ele está exercendo a dominação em Doca, percebemos então essa força também como destrutiva da Bildung. Não há na vivência de Doca o "processo de autodescobrimento e de orientação no mundo", como ocorre no tradicional romance de formação segundo Maas (2000, p. 62).

Nem mesmo a família possui esse papel de orientar Doca, uma vez que o pai dá a sua família a experiência de sentir dentro de casa o autoritarismo e o terror de um governo tirânico. Adorno e Horkheimer (1973) consideram a família um campo privilegiado de socialização do indivíduo, pois "a família não só depende da realidade social, em suas sucessivas concretizações históricas, mas também está socialmente mediatizada, mesmo em sua estrutura mais íntima" (ADORNO e HORKHEIMER, 1973, p. 133).

Esse aspecto é importante porque as relações familiares é o elemento medular em torno do qual gravita a autodiegese de Doca, compondo 25 dos 34 capítulos do romance. Revela-se o exercício da violência simbólica pelo pai de Doca, que é um militar. Desde o início do romance ficamos sabendo da postura autoritária do pai de Doca, que ele estabelece um ambiente insuportável dentro de casa, a ponto de haver "noites em que nenhum de nós respira"; são, pois, dias que mesmo a violência não sendo dirigida ao Doca, ele sente temor, fica acordado até "a mais alta madrugada" só para poder chorar, "com a cara enterrada sob o travesseiro" (ARAUJO, 2010, p. 21).

Conforme relata, todo esse sofrimento o faz "imaginar coisas horríveis, como a morte de papai e a felicidade da gente na fila do tobogã. E minha irmã e eu tomando sorvete a qualquer hora..." (ARAUJO, 2010, p. 21).

O relato é significativo, pois, implica que a existência do pai impede uma real felicidade da família, como se fosse uma metáfora de que a existência da Ditadura impedisse a felicidade da população. Não poder tomar sorvete a qualquer hora, significa que o pai tolhe a liberdade de sua esposa e de seus filhos, assim como a Ditadura tolheu a liberdade da população, de maneira tal que somos levados a equiparar o medo que eles sentiam do pai/esposo com a cultura do medo estabelecida pela Ditadura Civil-Militar, conforme é destacado por Alves (2005, p. 205): 
O uso generalizado e institucionalizado da tortura numa sociedade cria um "efeito demonstrativo" capaz de intimidar os que têm conhecimento de sua existência e inibir a participação política. A evidência da repressão de Estado criou uma "cultura do medo" na qual a participação política equiparou-se ao risco real de prisão e consequente tortura [e] coibiu a participação em atividades de oposição comunitária, sindical ou política. Esta cultura do medo tinha três importantes componentes psicológicos: o primeiro era o silêncio imposto à sociedade pela rigorosa censura [...]. Este silêncio imposto, provocou profundo sentimento de isolamento naqueles que sofriam diretamente a repressão e/ou exploração econômica. [...]. Amplos setores da população viram-se marginalizados e isolados de outros segmentos que poderiam oferecer-lhes apoio e ajuda. [...]. Parecia impossível enfrentar o poder do Estado. Um sentimento de total desesperança passou a prevalecer na sociedade [...] Silêncio, isolamento e descrença eram os fortes elementos dissuasivos da "cultura do medo

Existe uma violência simbólica que impele essa família ao silenciamento, ao sofrimento e a desesperança de que possam ser felizes. Os anos de chumbo, de fato, foram anos de medo, isso porque o autoritarismo desencadeou uma brutalidade em todos os níveis, inclusive nas microrrelações.

Conforme relato de Doca, essa brutalidade se consumou com Elisa, quando flagrada fumando. Reproduzimos o capítulo "Sem falar" na íntegra:

Agora que Elisa tem peitos grandes e pernas bem torneadas, papai também deu de vigiá-la na saída do colégio. O pior logo aconteceu: viu Elisa fumando, com as amigas, pés apoiados no muro da escola, blusão amarrado na cintura, saia enrolada. Falando diferente, parecendo carioca, com as palavras que papai proíbe que se diga na frente dele. Mas só na frente dele. Porque Elisa é a moça mais querida do ginásio, a mais louca, mais hippie.

Mamãe tinha arrumado um trabalho como datilógrafa no despachante da avenida, e por isso, não estava em casa quando Elisa chegou, com a bochechas vermelhas, toda feliz cantando uma canção do John Lennon.

Papai ficou de tocaia, como convém a um policial. Nem deu tempo de Elisa justificar o hálito de cigarro. Papai deu o primeiro tapa na boca. O segundo no rosto. O terceiro não tinha mais endereço certo, porque Elisa começou a espernear e a berrar e a maldizer a existência "daquele homem" na nossa casa, na nossa vida, "aquele animal". Assisti a tudo do vão da escada, com medo do papai e com muita vergonha de ver Elisa de bunda no chão, as pernas arranhadas, a fita do cabelo desfeita, sem poder reagir. Mais vergonha ainda de ser fraco, nervoso, chorão, de tomar remédio forte para o resto da vida, de não ter forças para brigar com um capitão.

- Por que é que você não some daqui de uma vez por todas e deixa a minha mãe em paz, hein? - desafiou Elisa, com uma voz de velha que eu nunca tinha ouvido.

- Cala a boca! Cala essa boca suja sua vagabunda!

Papai tirou a cinta. Fechei os olhos. Elisa era só soluços e salivas. Daquele dia em diante, não se ouviu mais a voz de Elisa dentro de nossa casa. Nem canção, nem piada, nem deboche, nem "passa o açucareiro". Elisa era de opinião. Prometeu que ia fugir com o primeiro que aparecesse (ARAUJO, 2010, p. 82-83, grifos nossos). 
parte para violência física, sem nem considerar o sentimento de felicidade de Elisa.

O capítulo é significativo de que os membros da família estão presos numa relação de força cujo caráter arbitrário do pai é irredutível. Tudo isso leva ao esfacelamento da família, de modo que conseguimos depreender que é em concomitância com o recrudescimento do regime político que a família sofre uma ruptura definitiva. Tal aspecto converge com o argumento dos teóricos de Frankfurt de que

[...] é ilusório pensar que se possa realizar uma família de pares iguais numa sociedade em que a humanidade não é autônoma e na qual os direitos humanos ainda não tenham sido realizados numa medida mais concreta do que a atual [...]. A família sofre com isso, como qualquer particular que aspira a sua própria emancipação; não haverá emancipação da família se não houver a do todo (ADORNO e HORKHEIMER, 1973, p. 143;147).

O pai viajava para Resende, que é uma cidade onde se localizou uma importante casa de tortura, e ficava longos períodos afastado de casa, enquanto a mãe "passou a trabalhar cada vez menos e a frequentar mais o Clube Militar, onde ficava horas fazendo 'joguinho' [...]. Voltava cheirando a cigarro e sem paciência de olhar meus trabalhos de escola" (ARAUJO, 2010, p. 89).

A consequência é o aumento da solidão e do sofrimento de Doca: "sem poder entender por que tudo na minha família tinha de ser assim, tudo cheio de raiva e de dor" (ARAUJO, 2010, p. 90). Não há alteridade em relação às suas vivências, de modo que "o problema que a violência coloca é o da ausência de um lugar de inteligibilidade e escuta para o sofrimento que dela advém, lugar que requer, como condição de sua possibilidade, o reconhecimento social da violência”. (SARTI, 2014, p. 81). Doca está sozinho para lidar com as violências simbólicas que o interpela, seja na escola, seja em casa, o que implica uma imposição do silêncio frente a violência e a falta de compreensão (Demonstraremos mais adiante que esse aspecto possui, inclusive, consequências diretas na estrutura do romance).

O último capítulo (“Ordem, sem lugar, sem rir, sem falar") é a cena de Doca brincando sozinho e pensando na situação da sua família:

Hoje passei a tarde inteira no tum-tum-tum, batendo bola na parede para ver se, de uma vez por todas, chego até o final. Ordem. Papai mal fala comigo, está distante, só conversa com mamãe para pedir que ela faça coisas. Sem lugar. Desde que Elisa se casou, mamãe virou uma dona de casa assustada e já não se arruma direito. Passa horas ao telefone 
trocando receitas novas de sapatinhos e gorros. Quando o carro do "senhor capitão" para no portão, corre para mudar o ambiente: desliga a tevê, vai para o fogão, liga o exaustor e finge que está mexendo a panela. Esconde debaixo da escada a cesta com novelos de lã e o enxoval do bebê. Sem rir. Que saco! Fico olhando para a cara de papai e de mamãe no jantar, eles mal se olham! Sem falar. Não abro o bico pra ninguém, mas estou contando os dias para me mudar daqui e, por isso, não penso mais em ser cadete coisa nenhuma. Vou fazer curso técnico de agronomia para estudar fora da cidade (ARAUJO, 2010, p. 93).

Assim, a narrativa, desde o seu início, progride de modo a acentuar o descontentamento e o desamparado de Doca. Consideramos que isso resulta diretamente do fato de que em nenhum momento a autodiegese de Doca "preconiza o desenvolvimento das qualidades e talentos inatos no indivíduo orientado para a vida em sociedade, para a prática de ações em prol do bem da coletividade" (MAAS, 2000, p. 31). A infelicidade dos pais é tanta, que começa a haver a omissão deles em relação ao filho, ocasionando em desamparo afetivo, de modo que ele já não pensa em fazer as vontades do pai e já não consegue mais presenciar a figura submissa que a mãe se tornara.

Conforme Maas (2002), na compreensão tradicional sobre o Bildungsroman, "devem ser consideradas como pertencentes ao gênero obras em cujo centro esteja a história de vida de um protagonista jovem, história essa que conduz, por meio de uma sucessão de enganos e decepções, a um equilíbrio com o mundo" (MAAS, 2000, p. 62). Contudo, no romance Ordem, não ocorre "um equilíbrio com o mundo" em relação à Doca. Existe uma passividade em Doca, decorrente do medo provocado por toda a violência simbólica que sofreu em casa e na escola, mas não podemos deixar de observar que, ao querer ir embora de casa, existe a esperança de uma renovação biográfica.

Seria, então, essa esperança de uma renovação biográfica parte de um processo de formação e de amadurecimento do herói ou, justamente, o reconhecimento do fracasso dessa formação?

A institucionalização da prática de tortura e o estabelecimento de uma cultura do medo pelo regime militar não representariam o insucesso da Bildung para uma grande parte de crianças e adolescentes que cresceram durante o Al-5? Acreditamos que sim e, por consequência, defendemos que o término do romance está mais inclinado para representar o insucesso da Bildung do que um amadurecimento crítico de Doca.

Em vista disso, concebermos que a forma como Leusa Araujo vincula o 
crescimento de Doca no período dos anos de chumbo da Ditadura Militar pode ser vista como uma subversão do Bildungsroman, pois, ao invés de narrar o desenvolvimento bem-sucedido de um indivíduo, é exposto o sofrimento, a solidão e desemparo de Doca. Dentro da narrativa, a Ditadura simboliza o insucesso de uma formação. A Ditadura, com sua violência invadindo o âmbito familiar e censurando a socialização política em esfera pública, buscou esfacelar o lastro necessário para o processo formativo para o sujeito livre. Não se pode esquecer, como assinala Adorno (1965), que as condições e as instituições sociais têm ação direta sobre os tipos de personalidade que se formam dentro de uma sociedade: "Isso significa que as grandes mudanças nas condições e nas instituições sociais têm ação direta sobre os tipos de personalidade que se formam dentro de uma sociedade" (ADORNO, 1965, p. 31, tradução nossa).

O regime militar gerou grandes impactos institucionais e culturais, que não são compatíveis com uma subjetividade livre. Com a ajuda de Adorno (2010), podemos compreender que o ideal iluminista da formação, nos termos da Bildung, partiu do pressuposto de uma forte autonomia do sujeito com relação à realidade. Esse processo formativo foi danificado, conforme Adorno (2010), devido as novas mediações históricas, como a II Guerra, o Nazismo, a Indústria Cultural, e no caso brasileiro, podemos incluir a Ditadura:

\begin{abstract}
A formação devia ser aquela que dissesse respeito - de uma maneira pura como seu próprio espírito - ao indivíduo livre e radicado em sua própria consciência, ainda que não tivesse deixado de atuar na sociedade e sublimasse seus impulsos. A formação era tida como condição implícita a uma sociedade autônoma: quanto mais lúcido o singular, mais lúcido o todo. Contraditoriamente, no entanto, sua relação com uma práxis ulterior apresentou-se como uma degradação a algo heterônomo, como percepção de vantagens de uma irresolvida bellum omnium contra omnes (ADORNO, 2010, p. 13).
\end{abstract}

O argumento do autor em relação ao conceito de Bildung nos possibilita compreender como essa formação é condenada ao fracasso quando os sujeitos, como Doca, não estão inseridos em uma "sociedade autônoma".

Assim, ao levarmos em consideração o conceito de Bildung em nossa interpretação do romance Ordem, não se trata de conceber uma "continuidade" ou uma atualização do Bildungsroman; nesse aspecto de "continuidade" ou atualização, seria legítimo um romance que abordasse o processo de aprendizado contra o regime militar, tendo, por exemplo, um jovem que, mesmo inserido em um contexto 
de violência simbólica que busca legitimar o regime ditatorial, busca se contrapor à Ditadura, e isso poderia surgir de várias formas.

Mas, ao optar pelo insucesso da Bildung, o romance ressalta toda a violência e desamparo sentido por Doca, mobilizando, consequentemente, o horror para 0 esclarecimento do leitor de que jamais esse período histórico pode se repetir, e isto contribui para "a sensibilização, sobretudo das novas gerações, sobre esse passado cujas permanências ainda se fazem presentes em nossa cultura política autoritária" (PELATTO, 2017, p. 738).

Em outras palavras, a conclusão que deriva de nossa análise da autodiegese de Doca consiste, portanto, em propormos que a sua vivência realiza "uma problematização da natureza do próprio processo de formação vivenciado pelo protagonista, o que contribui por sua vez para o estabelecimento de uma perspectiva crítica para além do conceito tradicional e "ortodoxo" de Bildungsroman" (MAAS, 2000 , p. 257). Essa "problematização da natureza do processo de formação" implica, a nosso ver, a problematização de enriquecimento subjetivo e formação de consciência crítica para quem está vivendo em plena Ditadura, o que revela, por sua vez, a opção ética da escritora ao optar pelo insucesso da Bildung, pois isto é se opor contra a experiência catastrófica que, durante 21 anos, deformou a condição humana, reduzindo o sujeito a mero objeto e incapacitando-o para a ação política a partir do arbítrio de um Estado autoritário.

Há no término do romance um senso de inconclusão. Não temos acesso à vida adulta de Doca, o que é mais uma subversão ao Bildungsroman tradicional. $\mathrm{Na}$ esteira dos estudos de Delbrassine (2006), Cruvinel (2009) assinala que o romance juvenil contemporâneo representa uma fração do Bildungsroman, no sentido em que possuem o aspecto de "um avatar frequentemente fragmentário do romance de formação ou de aprendizagem" (DELBRASSINE, 2006 apud CRUVINEL, 2009, p. 27). Assim, o fato de não termos acesso ao período da maior idade de Doca nos leva intuir no prejuízo psicológico que ele terá nesse período da sua vida, devido ao desamparo familiar e as violências simbólicas sofridas, e para isso contribui a própria estrutura fragmentária pela qual é composto o romance. Sendo assim, e tendo em vista as análises realizas até aqui, compreende-se que a figuração do passado no romance Ordem não possui "autonomia em relação a todas as subjetividades individuais" (JAMESON, 2007, p. 198), afinal, conforme argumenta Jameson (2007), "o romance histórico não deve mostrar nem existências individuais nem 
acontecimentos históricos, mas a interseção de ambos" (JAMESON, 2007, p. 192). Por isso, a autodiegese de Doca torna-se fundamental como experiência individual de insucesso de Bildung em contextos políticos e sociais em que a violência histórica foi muito forte, desempenhando papel decisivo na constituição das instituições.

\section{Considerações finais}

Esperamos ter comprovado, à luz das passagens apresentadas e analisadas até aqui, a nossa hipótese de que a narrativa representa o insucesso da Bildung de Doca, devido a transição da infância à adolescência ocorrer justamente nos anos de chumbo da Ditadura Civil-Militar. Não ocorre o típico "equilíbrio entre a subjetividade e a atividade voltada para o mundo exterior" do tradicional Bildungsroman (MAAS, 2000 , p. 212). Ordem está, de fato, longe de ser uma narrativa sobre integração e conciliação de um indivíduo com a sociedade na qual está inserido. No programa do Bildungsroman, a tônica é que o sujeito "se apresenta em indissolúvel relação com a formação histórica", de maneira tal que "o tempo se introduz no interior do homem, impregna-lhe toda a imagem, modificando a importância substancial de seu destino e de sua vida" (BAKHTIN, 2011, p. 221, 223). Dessa maneira, foi possível apreender que o perfil da identidade de Doca se apresenta em indissolúvel relação com a Ditadura Civil-militar, a qual modificou de forma substancial sua vida, mesmo que a narrativa não enfoque cenas de violência física, explicitações de agressão, ou de imagens de militares armados.

Publicado em 2010, a fortuna crítica de Ordem ainda é bem exígua, porém pode render frutíferas análises acerca de sua temática social. O romance de Leusa Araujo resgata uma memória ainda dolorida de um tempo sombrio, por isso se faz pungente e atual, dado que nesta segunda década do século XXI, a ascensão expressiva de discursos negacionistas e revisionistas demonstram a intenção de apagamento dos eventos ocorridos durante a Ditadura Civil-Militar no Brasil por grupos sociais com posições ideológicas alinhadas à extrema-direita.

Por outro lado, o romance de Leusa Araujo também é significativo da qualidade da produção contemporânea de literatura juvenil. É importante destacar esse aspecto, porque a literatura juvenil permanece por vezes marginalizada, sem pesquisas mais sistemáticas na área da teoria, da crítica e da circulação, o que nos 
leva a constatarmos que literatura juvenil se encontra ainda como "uma prática em vias de consagração [que] coloca incessantemente aos que a ela se entregam a questão de sua própria legitimidade" (BOURDIEU, 2007, p. 155).

Nesse sentido, Aguiar, Ceccantini e Martha (2012, p. 8) demonstram a existência "[...] de uma geração de autores que, após o momento de consolidação e franca expansão do gênero juvenil (1980-2000), vem renovando de forma bastante criativa o cenário da literatura juvenil brasileira". Um dos aspectos assinalados pelos autores é a busca de novas soluções estéticas, empreendida pelos escritores contemporâneos de narrativas juvenis, com o objetivo de "[...] atender (e romper) as expectativas das novas gerações de leitores [e] têm explorado com ousadia temas e formas afinados com o século XXI" (AGUIAR; CECCANTINI; MARTHA, 2012, p.8). Leusa Araujo, sem dúvida, pertence a essa nova geração, por isso também esperamos que esse artigo contribua para os estudos sobre a literatura juvenil.

\section{Referências Bibliográficas}

ADORNO, Theodor; HORKHEIMER, Max. A indústria cultural: o esclarecimento como mistificação das massas. In: Dialética do esclarecimento: fragmentos filosóficos. Rio de Janeiro: Zahar, 1985, p. 99-138.

ADORNO, Theodor. Teoria da semiformação. In: PUCCI, Bruno; ZUIN, Antônio; LASTÓRIA, Luiz (Org.). Teoria crítica e inconformismo: novas perspectivas de pesquisa. Campinas: Autores Associados, 2010. p. 7-40.

. La personalidad autoritaria. Buenos Aires: Editorial Proyección, 1965.

ADORNO, Theodor; HORKHEIMER, Max. Temas Básicos da Sociologia. São Paulo: Cultrix, 1973.

ALVES, Maria Helena Moreira. Estado e oposição no Brasil - 1964-1984. Bauru: Edusc, 2005.

AGUIAR, Vera Teixeira; CECCANTINI, João Luís; MARTHA, Alice Aurea Penteado (Orgs.). Narrativas juvenis: geração 2000. São Paulo: Cultura Acadêmica, Assis, SP: ANEP, 2012.

ARAUJO, Leusa. Ordem, sem lugar, sem rir, sem falar. Ilustrações de Nelson Provazi. São Paulo: Scipione, 2010.

BAKHTIN, Mikhail. O romance de educação e sua importância na história do realismo. In: Estética da criação verbal. São Paulo: Ed. Martins Fontes, 2011, p. 203-258.

BOURDIEU, Pierre. O poder simbólico. Rio de Janeiro: Editora Bertrand, 1989. 
BOURDIEU, Pierre. O mercado de bens simbólicos. In: A economia das trocas simbólicas. São Paulo: Perspectiva, 2007. p. 99- 181.

A dominação masculina. 3 ed. Rio de Janeiro: Bertrand Brasil, 2003.

COLOMER, Teresa. A formação do leitor literário: narrativa infantil e juvenil atual. São Paulo: Global, 2003.

CRUVINEL, Larissa Warzocha Fernandes. Narrativas juvenis brasileiras: em busca da especificidade do gênero. 2009. 188 f. Tese (Doutorado em Letras) - Universidade Federal de Goiás, UFG, 2009.

DUARTE, R. G.; GONZALEZ, E. Pensando a América Latina: música popular, política e Ensino de História. CERRI, L. F. (Org.). Ensino de História e Educação: olhares em convergência. Ponta Grossa: Editora UEPG, 2006.

HOBSBAWM, Eric. Era dos Extremos: o breve século XX: 1914-1991. São Paulo: Companhia das Letras, 1995.

JAMESON, Fredric. O romance histórico ainda é possível? Novos Estudos CEBRAP. São Paulo, n.77, p. 185-203, 2007.

MAAS, Wilma Patrícia. O cânone mínimo. O Bildungsroman na história da literatura. São Paulo: Editora Unesp, 2000.

MARTINS, Georgina. Narradores da exclusão ou a infância pobre na literatura brasileira contemporânea. Estudos de Literatura Bras. Contemp., Brasília, n.41, p. 19-148, 2013.

PERLATTO, Fernando. História, literatura e a ditadura brasileira: historiografia e ficções no contexto do cinquentenário do golpe de 1964. Revista Estudos Históricos, Rio de Janeiro, v. 30 , n. 62 , p. $721-740,2017$.

REUTER, Yves. Introdução à análise do romance. São Paulo: Martins Fontes, 1995.

SARTI, Cynthia. A construção de figuras da violência: a vítima, a testemunha. Revista Horizontes Antropológicos, Porto Alegre, vol. 20, n. 42, p. 77-105, 2014. 